\title{
ANÁLISE DOS PRODUTOS GASOSOS DA HIDROPIRÓLISE DE CARVÃO MINERAL POR CROMATOGRAFIA GASOSA
}

\author{
R. B. RIBEIRO ${ }^{1}$, R. S. NASCIMENTO ${ }^{1}$, V. V. F. JÚNIOR ${ }^{1}$, F. P. GUTERRES ${ }^{1}$ e \\ A. R. C. MUNIZ ${ }^{1}$ \\ ${ }^{1}$ Universidade Federal do Pampa, Departamento de Engenharia Química \\ E-mail para contato: romulob.ribeiro@yahoo.com.br
}

\begin{abstract}
RESUMO - O carvão é o mais abundante recurso energético não renovável e a mais importante reserva energética do planeta. As reservas mais significativas de carvão no Brasil são as da Bacia do Paraná, localizadas na região sul do país, onde $38 \%$ do carvão nacional está localizado na cidade de Candiota/RS. A principal utilização do carvão mineral é para geração de energia elétrica, porém, devido ao baixo poder calorífico do carvão dessa região, estudos são necessários para melhor aproveitamento dessa matéria prima, sendo uma das principais técnicas a hidropirólise. Essa técnica consiste na decomposição térmica mediante aquecimento do carvão juntamente com um solvente, em um recipiente fechado, sob pressão e alta temperatura. Nessas condições ocorrem reações de craqueamento das macromoléculas do carvão e formação de hidrocarbonetos de menor peso molecular. Portanto este trabalho tem por objetivo a realização de ensaios de hidropirólise do carvão da jazida de Candiota-RS e identificação de compostos da fase gasosa através de GC-TCD. Para isso, foram realizados experimentos utilizando um reator de alta pressão e temperatura, operando em modo batelada, utilizando-se água como solvente. Nos gases gerados foi identificada uma produção significativa de hidrogênio e metano além de presença de gases não condensáveis como dióxido de carbono e etano.
\end{abstract}

\section{INTRODUÇÃO}

\subsection{Carvão mineral}

O carvão mineral é uma rocha sedimentar carbonácea proveniente da decomposição de matéria vegetal depositada em regiões pantanosas do período carbonífero, entre 345 a 280 milhões de anos atrás (Riegel e Kent, 2007; Perry et al, 2008; Speight, 2008). Estima-se que o Brasil possua reservas totalizando 6,6 bilhões de toneladas, contudo, esta quantia equivale somente a $0,7 \%$ da reserva mundial (BP, 2016). Das reservas brasileiras de carvão, $89 \%$ encontram-se no Rio Grande do Sul, sendo que 39\% localizam-se no município de Candiota/RS (Süffert, 1997). Dessa maneira observa-se um grande potencial a ser explorado na região.

O minério da jazida de Candiota é atualmente explorado com o único objetivo de geração de energia termoelétrica. No estudo realizado por Stüffert (1997) também qualificouse os carvões desta jazida como pertencendo a categoria de carvão betuminoso de alto volátil C, não coqueificável, com teor de cinzas médio próximo de $52 \%$, teor de enxofre inferior a 
$2 \%$ e poder calorífico superior, em base seca, próximo de $3.300 \mathrm{cal} / \mathrm{g}$, com pequenas alterações de valores observadas em todos os blocos analisados.

Segundo Clifford e Song (2011) recomenda-se a utilização de carvões subbetuminosos e betuminosos para a hidropirólise pois são mais estáveis à temperatura e aos solventes, também por apresentarem maiores teores de impurezas esses proporcionam uma baixa eficiência na queima para geração de energia, devido ao baixo poder calorífico.

\subsection{Processos de conversão térmica do carvão}

A hidropirólise consiste na degradação térmica de matéria orgânica na ausência parcial ou total de oxigênio com adição de solvente a fim de gerar produtos sólidos, líquidos e gasosos com propriedades diferentes da matéria-prima. Este processo compreende uma série de reações químicas e físicas que ocorrem em pressões de até 2.500 psi e temperaturas entre 250 e $550^{\circ} \mathrm{C}$ (Liang et al, 2014). O objetivo principal da hidropirólise é gerar produtos com uma razão de hidrogênio-carbono maior do que a encontrada no carvão, e tem por objetivo secundário a remoção de impurezas como enxofre, nitrogênio e oxigênio (Riegel e Kent, 2007).

Segundo Riegel e Kent (2007) e Li et al (2008), observa-se que ocorre um aumento na produção de gases combustíveis em condições de pressão e temperatura altas, com a presença de hidrogênio na atmosfera de reação e com partículas menores de carvão. Conforme Yan et al (2014), em temperaturas e pressões de hidrogênio maiores, a formação de moléculas orgânicas menores é favorecida, pois o aumento da temperatura auxilia na decomposição das macromoléculas do carvão e a presença de hidrogênio promove a estabilização dos fragmentos formados.

\subsection{Cromatografia gasosa}

A técnica de cromatografia é baseada na separação dos componentes da amostra que se deseja analisar. Inicialmente injeta-se a amostra no equipamento, esta então é misturada a fase móvel, no caso da cromatografia líquida o analíto é misturado a um solvente, e na cromatografia gasosa a um gás inerte, geralmente hélio ou nitrogênio. Em seguida, a fase móvel percola por uma coluna cromatográfica (fase estacionária), e devido a diferenças de interação dos componentes presentes na fase móvel com a fase estacionária, ocorre a separação dos mesmos ao longo da coluna. Ao fim da mesma, o analíto é avaliado conforme o tempo de residência na coluna. Em conjunção com o processo de separação utiliza-se sistemas de detecção de forma a determinar a composição da amostra, um sistema relativamente simples e de ampla aplicação é o detector por condutividade térmica (TCD), no qual analisase a alteração causada pelos compostos na condutividade térmica do gás de arraste, dessa maneira e em conjunto com o tempo de retenção na coluna, é possível identificar os compostos presentes na amostra (Skoog et al, 1980; Scott, 1996).

Este trabalho tem por objetivo realizar a hidropirólise do carvão mineral de Candiota e verificar a composição dos produtos gasosos da mesma através de análise por GC-TCD.

\section{MATERIAL E MÉTODOS}


Os testes de hidropirólise foram realizados em reator de alta pressão da marca Parr série 4575/4576 HP/HT Pressure Reactors do Laboratório de Energia e Carboquímica. Este reator possui um vaso cilíndrico, com capacidade de $250 \mathrm{ml}$, e pode operar em condições máximas de temperatura e pressão de $500^{\circ} \mathrm{C}$ e 5000 psi, respectivamente. A temperatura do forno, o sistema de resfriamento do reator e agitação são controlados por controlador da marca Parr modelo 4848 Reactor Controller, ambos equipamentos são mostrados na Figura 1.

Os ensaios foram realizados em batelada nas condições que potencializassem a geração de gases combustíveis não-condensáveis. Portanto carregou-se o vaso reacional com $40 \mathrm{~g}$ de carvão pulverizado com diâmetro médio de $230 \mu \mathrm{m}$ proveniente da jazida de Candiota e $80 \mathrm{~g}$ de água deionizada, a pressão inicial do sistema foi regulada adicionando gás argônio até $1000 \mathrm{psi}$, ajustou-se a temperatura no forno para $495^{\circ} \mathrm{C}$, obtendo-se uma temperatura no interior do reator de $460^{\circ} \mathrm{C}$. Ao atingir a temperatura de reação iniciou-se a retirada e consequente análise das amostras dos gases pelo GC-TCD.

Figura 1 - Reator de alta pressão e temperatura e controlador

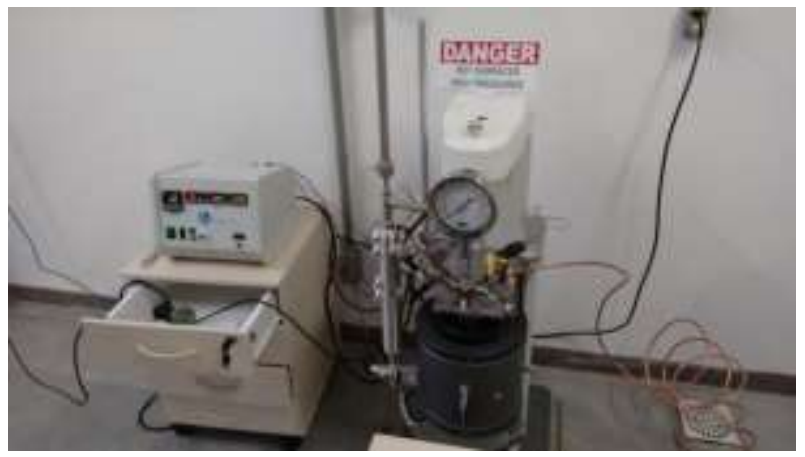

Analisou-se os gases gerados nos ensaios de hidropirólise quanto a sua composição através da cromatografia gasosa, em cromatógrafo gasoso GC-2014 da marca Shimadzu, com coluna de 15 pés, recheio Carboxen-1000 de 60/80 mesh, diâmetro de 1/8" SS e detector de condutividade térmica (GC-TCD), exposto na Figura 2. Usou-se uma temperatura de injeção de $225^{\circ} \mathrm{C}$ utilizando $\mathrm{N}_{2}$ como gás de arraste com vazão de $30 \mathrm{ml} / \mathrm{min}$, o perfil de temperatura da coluna foi ajustado conforme o fabricante, aquecendo inicialmente a $35^{\circ} \mathrm{C}$ por um período de $5 \mathrm{~min}$, em seguida a uma taxa de $20^{\circ} \mathrm{C} / \mathrm{min}$ elevou-se a temperatura da coluna até $225^{\circ} \mathrm{C}$ mantendo-a por mais $15 \mathrm{~min}$, completando o tempo de análise de 29,5 min.

Figura 2 - Cromatógrafo gasoso

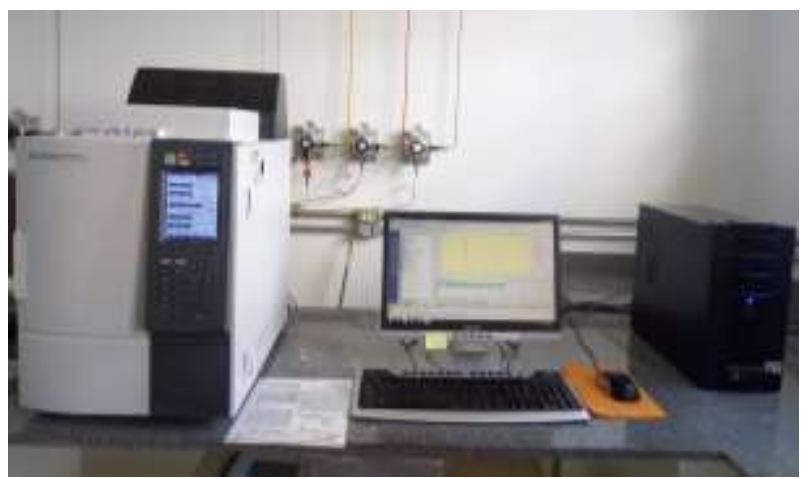




\section{RESULTADOS E DISCUSSÃO}

Identificou-se a produção de hidrogênio, metano, dióxido de carbono e etano no ensaio de hidropirólise ao final de 4 horas de reação, como demonstra a Figura 3. Os picos de hidrogênio e metano apresentam maior intensidade, seguidos de dióxido de carbono e etano. $\mathrm{O}$ pico de argônio apresenta intensidade negativa pois possui condutividade térmica menor que o gás de arraste, nitrogênio.

Figura 3 - Cromatograma dos gases da hidropirólise de carvão mineral

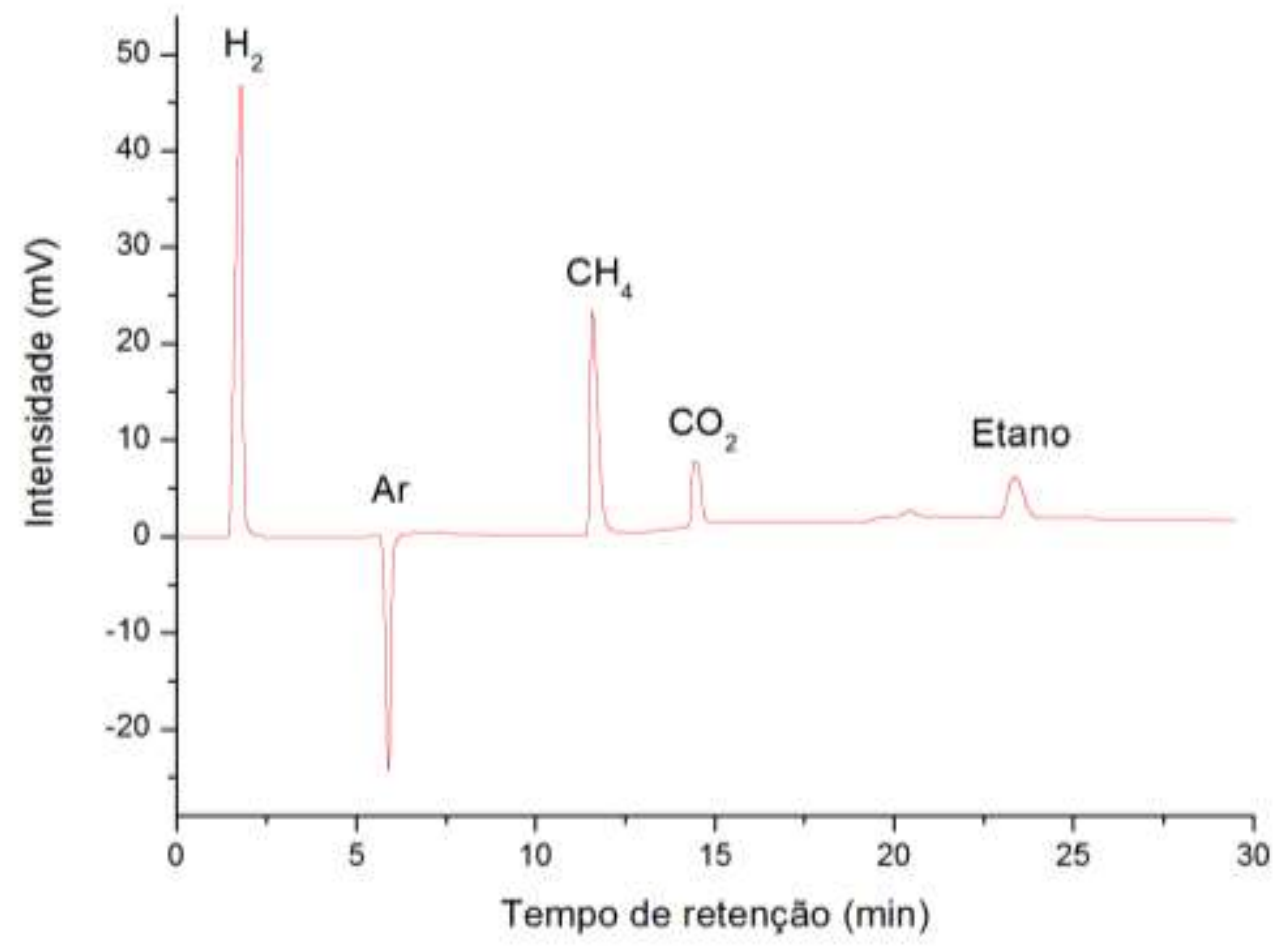

Segundo Michels e Landais (1994), a adição de água, como solvente, no processo de pirólise proporciona pressão ao meio reacional devido a vaporização de parte da água em sistema fechado, e ao mesmo tempo promove um meio quimicamente ativo, pois fornece hidrogênio à reação. Silverman et al (1986) também explica que no processo de hidropirólise a adição de vapor d'água aumenta a produção de hidrogênio e metano por meio do craqueamento do material carbonáceo pobre em hidrogênio, outro fator levantado pelos autores é a diminuição da quantidade de monóxido de carbono na fase gasosa, devido a reações de water-gas shift, na qual vapor d'água e monóxido de carbono reagem formando hidrogênio e dióxido de carbono. Ademais, notou-se a produção de etano no gás de hidropirólise sendo um material com potencialidade de utilizações. 


\section{CONSIDERAÇÕES FINAIS}

A partir dos resultados obtidos observa-se que o processo de hidropirólise, pode ser uma alternativa de utilização para o carvão de Candiota, visto a possibilidade de produção de gases de alto valor econômico e industrial, como hidrogênio, metano e etano. A cromatografia gasosa se mostra eficiente para o presente caso, apresentando uma boa separação e definição gráfica dos compostos. Ademais, verifica-se a necessidade de estudos futuros, mais aprofundados sobre a viabilidade econômica do processo e possíveis utilizações desses insumos.

\section{REFERÊNCIAS}

SILVERMAN, J.; FRIEDMAN, J.; ULLMAN, A. Z. Hydropyrolysis process, 1986. Google Patents. Disponível em: <https://www.google.ch/patents/CA1199039A?cl=en>. Acesso em: fev. 2017.

RIEGEL, E. R.; KENT, J. A. Kent and Riegel's Handbook of Industrial Chemistry and Biotechnology. 2007.

PERRY, R. H.; BENSKOW, L. R.; BEIMESCH, W. E. Perry's Chemical Engineers' Handbook. Nova Iorque: McGraw-Hill, 2008.

SPEIGHT, J.G. Handbook of Coal Analysis. John Wiley \& Sons. New Jersey: Series Editor, 2005.

SPEIGHT, J.G. Synthetic fuel Handbook - Properties, Process and Performance. McGrawHill Handbooks, 2008.

BP. Statistical Review of World Energy, June 2016. BRITISH PETROLEUM Disponível em: <http://www.bp.com/en/global/corporate/about-bp/energy-economics/statistical-reviewof-world-energy.html>. Acesso em: nov. 2016.

SÜFFERT, T. Carvão nos Estados do Rio Grande do Sul e Santa Catarina. Companhia de Pesquisa de Recursos Minerais. projeto nº 21, 1997.

SKOOG, D. A.; WEST, D. M.; HOLLER, F. J.; CROUCH, S. R. Principles of Instrumental Analysis. Editora Thomson, 1998.

LI, X.; HU, H.; JIN, L.; HU, S.; WU, B. Approach for promoting liquid yield in direct liquefaction of Shenhua coal. Fuel Processing Technology, v. 89, n. 11, p. 1090-1095, 2008.

YAN, J.; BAI, Z.; LI, W.; BAI, J. Direct liquefaction of a Chinese brown coal and CO2 gasification of the residues. Fuel, v. 136, p. 280-286, 2014.

CLIFFORD, C. B.; SONG, C. Direct liquefaction (DCL) processes and technology for coal and biomass conversion. Woodhead Publishing Series in Energy. v. 19, p. 105-154, 2011. 
SCOTT, P. W. R. Chromatographic detectors: Design, function, and operation. Marcel Dekker, Inc. 1996.

LIANG, M.; WANG, Z.; ZHENG, J.; et al. Hydrous pyrolysis of different kerogen types of source rock at high temperature-bulk results and biomarkers. Journal of Petroleum Science and Engineering, v. 125, p. 209-217, 2015.

MICHELS, R.; LANDAIS, P. Artificial coalification: Comparison of confined pyrolysis and hydrous pyrolysis. Fuel, v. 73, n. 11, p. 1691-1696, 1994. 